\title{
Does Particulate Matter Really Affect Sinusitis?
}

\author{
Suha $\operatorname{Lim}^{1,2,3}$ (D) Hyun-Woo Shin ${ }^{1,2,3,4,5}$ (D) \\ ${ }^{1}$ Obstructive Upper airway Research Laboratory, Department of Pharmacology, Seoul National University College of Medicine, Seoul; \\ ${ }^{2}$ Department of Biomedical Sciences, Seoul National University Graduate School, Seoul; ${ }^{3}$ Cancer Research Institute, Seoul National University \\ College of Medicine, Seoul; ${ }^{4}$ Department of Otorhinolaryngology-Head and Neck Surgery, Seoul National University Hospital, Seoul; \\ ${ }^{5}$ Sensory Organ Research Institute, Seoul National University College of Medicine, Seoul, Korea
}

Sinusitis is caused by many risk factors, such as smoking, colds, age, allergens, and air pollutants. Mortality from chronic respiratory diseases has increased from 1990 to 2017; this change is closely correlated with industrialization and urbanization [1], which are social changes that have resulted in outdoor and indoor air pollution. According to the U.S. Environmental Protection Agency, the most common and hazardous air pollutants are particulate matter (PM), ozone, sulfur dioxide, nitrogen dioxide, lead, and carbon monoxide. In particular, PM contributes to several major diseases, such as cardiovascular and circulatory diseases, chronic respiratory diseases, and cancer [2].

It is well known that PM affects the lower respiratory tract. Short-term exposure to PM is highly associated with increased hospitalizations for chronic obstructive pulmonary disease, asthma, and pneumonia [3]. In vitro studies have reported that exposure to PM induced interleukin (IL)-6 production by alveolar macrophages and tumor necrosis factor-alpha, IL-1 $\beta$, granulocytemacrophage colony-stimulating factor, and IL-8 by bronchial epithelial cells [4,5]. Several in vivo studies have also demonstrated the effect of PM on the lungs. For example, Brandt et al. [6] exposed mice to diesel exhaust particles (DEPs) with house dust mites (HDM) for 3 weeks. DEPs with HDM caused $\mathrm{T}_{\mathrm{H}} 2 /$ $\mathrm{T}_{\mathrm{H}} 17$ responses, eosinophil and neutrophil infiltration, mucus hypersecretion, and airway hyperresponsiveness, which are characteristics of severe asthma.

\footnotetext{
- Received November 3, 2021

Accepted November 4, 2021

- Corresponding author: Hyun-Woo Shin

Department of Pharmacology, Seoul National University College of

Medicine and Department of Otorhinolaryngology-Head and Neck Surgery,

Seoul National University Hospital, 103 Daehak-ro, Jongno-gu,

Seoul 03080, Korea

Tel: +82-2-740-8285, Fax: +82-2-745-7996

E-mail: charlie@snu.ac.kr
}

The impact of PM on the upper airway is similar to its impact on the lower airway. Although some epidemiological studies have reported inconsistent findings regarding correlations between PM and sinusitis [7], a recent case-control study demonstrated that $\mathrm{PM}_{2.5}$ exposure showed a significant association with chronic rhinosinusitis (CRS) diagnosis. The authors in this study investigated 2,034 non-allergic CRS patients and 4,068 controls and recorded exposure levels up to 60 months before the date of diagnosis [8].They divided the patients into maxillary, frontal, ethmoidal, sphenoidal, and severe (presence in all four sinuses) sinusitis. The odds ratio (OR) was particularly high for ethmoidal sinusitis, as the ethmoid sinuses have the widest area for contact with air. The OR for severe sinusitis progressively increased and peaked at 36 months $(\mathrm{OR}, 7.91)$ [8]. These results furnish strong evidence that long-term exposure to PM affects the likelihood of being diagnosed with CRS.

PM induces epithelial barrier dysfunction, leading to the pathogenesis of CRS. PM exposure in human nasal epithelial cells reduced transepithelial electrical resistance and the expression of tight junction proteins. Because many air pollutants produce reactive oxygen species, the authors activated an antioxidant transcription factor, nuclear factor-E2 p45-related factor 2 (Nrf2). Nrf2 effectively restored epithelial barrier function [9]. Furthermore, DEPs induce the epithelial-to-mesenchymal transition (EMT), which is a process involving the loss of epithelial polarity and junctional proteins [10]. PM-induced EMT could even influence the development of nasal polyps, the most severe type of CRS. In mice exposed to DEPs and HDM intranasally or through a nose-only inhalation system for 8 weeks (before that, HDM was administrated for sensitization and maintenance of inflammation), it was found that DEPs with HDM significantly increased nasal polyp numbers and epithelial disruption. The authors found the zinc finger E-box-binding homeobox 2

Copyright @ 2021 by Korean Society of Otorhinolaryngology-Head and Neck Surgery.

This is an open-access article distributed under the terms of the Creative Commons Attribution Non-Commercial License (https://creativecommons.org/licenses/by-nc/4.0)

which permits unrestricted non-commercial use, distribution, and reproduction in any medium, provided the original work is properly cited. 
(ZEB2) protein is the key factor in DEP-mediated EMT [10]. This study demonstrated that PM participates in nasal polyp formation by inducing the EMT.

Air pollution is a mixture of thousands of components, and exposure is often unclear in terms of time and concentration. Thus, it is difficult to determine causality. Nevertheless, many researchers have shown that air pollution, especially PM, can cause and exacerbate sinusitis. These studies demonstrate the importance of environmental factors in sinusitis. However, further studies are needed to fully elucidate the role of PM. For example, PM exposure in childhood and adolescence could substantially affect the development of sinusitis. Therefore, recording PM exposure from infancy to adulthood might be important. In addition, when epithelial disruption by EMT occurs, PM can easily penetrate the nasal tissue. PM can influence neutrophils, eosinophils, macrophages, or fibroblasts, particularly if the EMT takes place. There is also a need for research to clarify the main component of PM that causes sinusitis and/or the implication of $\mathrm{PM}$ in endotypes of CRS.

\section{CONFLICT OF INTEREST}

No potential conflict of interest relevant to this article was reported.

\section{ORCID}

Suha Lim https://orcid.org/0000-0002-1054-0145

Hyun-Woo Shin https://orcid.org/0000-0002-4038-9992

\section{ACKNOWLEDGMENTS}

This work was supported by the Education and Research Encouragement Fund of Seoul National University Hospital (2021).

\section{AUTHOR CONTRIBUTIONS}

Conceptualization: all authors. Data curation: all authors. Writing-original draft: SL.Writing-review \& editing: HWS.

\section{REFERENCES}

1. Xie M, Liu X, Cao X, Guo M, Li X.Trends in prevalence and incidence of chronic respiratory diseases from 1990 to 2017. Respir Res. 2020 Feb;21(1):49.

2. Lim SS, Vos T, Flaxman AD, Danaei G, Shibuya K, Adair-Rohani H, et al. A comparative risk assessment of burden of disease and injury attributable to 67 risk factors and risk factor clusters in 21 regions, 1990-2010: a systematic analysis for the Global Burden of Disease Study 2010. Lancet. 2012 Dec;380(9859):2224-60.

3. Zanobetti A, Schwartz J, Dockery DW. Airborne particles are a risk factor for hospital admissions for heart and lung disease. Environ Health Perspect. 2000 Nov;108(11):1071-7.

4. Mutlu GM, Green D, Bellmeyer A, Baker CM, Burgess Z, Rajamannan $\mathrm{N}$, et al. Ambient particulate matter accelerates coagulation via an IL-6-dependent pathway. J Clin Invest. 2007 Oct;117(10):2952-61.

5. Bayram H, Devalia JL, Sapsford RJ, Ohtoshi T, Miyabara Y, Sagai M, et al. The effect of diesel exhaust particles on cell function and release of inflammatory mediators from human bronchial epithelial cells in vitro. Am J Respir Cell Mol Biol. 1998 Mar;18(3):441-8.

6. Brandt EB, Kovacic MB, Lee GB, Gibson AM, Acciani TH, Le Cras TD, et al. Diesel exhaust particle induction of IL-17A contributes to severe asthma. J Allergy Clin Immunol. 2013 Nov;132(5):1194204.e2.

7. Leland EM, Zhang Z, Kelly KM, Ramanathan M Jr. Role of environmental air pollution in chronic rhinosinusitis. Curr Allergy Asthma Rep. 2021 Sep;21(8):42.

8. Zhang Z, Kamil RJ, London NR, Lee SE, SidhayeVK, Biswal S, et al. Long-term exposure to particulate matter air pollution and chronic rhinosinusitis in nonallergic patients. Am J Respir Crit Care Med. 2021 Oct;204(7):859-62.

9. London NR Jr, Tharakan A, Rule AM, Lane AP, Biswal S, Ramanathan M Jr. Air pollutant-mediated disruption of sinonasal epithelial cell barrier function is reversed by activation of the Nrf2 pathway. $\mathrm{J}$ Allergy Clin Immunol. 2016 Dec;138(6):1736-8.e4.

10. Lee M, Lim S, Kim YS, Khalmuratova R, Shin SH, Kim I, et al. DEPinduced ZEB2 promotes nasal polyp formation via epithelial-tomesenchymal transition. J Allergy Clin Immunol. 2021 May 4 [Epub]. https://doi.org/10.1016/j.jaci.2021.04.024. 